\title{
Characterization of As-Deposited Crystalline NiTi Thin Films
}

\author{
D. Bronfenbrenner,* V. Radmilovic, ** S. McHugo, *** R. Gronsky* \\ *Materials Science and Engineering, University of California, Berkeley, CA 94720 \\ ** National Center for Electron Microscopy, Lawrence Berkeley National Lab, Berkeley, CA 94720 \\ ***Nitinol Devices \& Components Inc., 47600 Westinghouse Dr., Fremont, CA 94539
}

Nickel-titanium alloys are popular in engineering applications because of their shape memory characteristics and biocompatibility. The shape memory effect is due to a reversible martensitic phase transformation upon heating and cooling through a critical temperature that varies with composition. Bulk NiTi has been used in many industrial and biomaterial applications due to its superelastic and shape memory behavior but applications in thin film morphologies has been limited. Techniques have been developed to grow thin films using various sputter deposition [1] and laser ablation [2] techniques. These films are often grown in an amorphous state, which then requires a subsequent annealing step after deposition to obtain a crystalline product to manifest shape-memory behavior. Recent work has shown that martensite in NiTi thin films can be directly deposited with consistent transformation temperatures and no need for a post-deposition annealing treatment.

Equiatomic sputter-deposited NiTi thin films were obtained with varying thicknesses ranging from 4 to $5 \mu \mathrm{m}$. The transformation temperature profile of the NiTi thin films were verified by differential scanning calorimetry. Four samples were collected from different locations on the sputtering surface to assess uniformity throughout the film. All four samples show a martensite structure at room temperature with an austenite transformation temperature of $\sim 80^{\circ} \mathrm{C}$. To confirm the crystallinity of the material, a diffraction profile was obtained using the 2-1 beam line at the Stanford Synchrotron Radiation Laboratory with a $\lambda=1.54047$. The diffraction profile in Figure 1 shows very sharp welldefined peaks as expected for a fully-crystalline material. To verify the martensite structure, transmission electron microscopy was performed on both planar and cross sectional samples using a JEOL 200CX microscope with a side-entry double-tilt goniometer stage operating at $200 \mathrm{kV}$. The diffraction pattern in Figure 2 is of the martensite in the [001] zone axis orientation. The micrograph in Figure 3 shows columnar growth of the film perpendicular to the substrate and Figure 4 shows the strong presence of twinning within the martensite grains. The columns are not continuous through the thickness of the film, but do have an average width of around $100 \mathrm{~nm}$. From a planar perspective, the grain size averages about $100 \mathrm{~nm}$ with a range of 50-500 $\mathrm{nm}$. The micrographs confirm that the film exists largely in a twinned martensite state.

As-depostied crystalline thin film NiTi can be sputter deposited to form the shape memory martensite structure at room temperature without a post annealing step. These films show a high degree of crystallinity that is textured in a columnar structure.

References:

1. Y. Fu, W. Huang, H. Du, X. Huang, J. Tan, X. Gao, Surface Coatings and Tech. 145 (2001) 107.

2. K. Ikuta, M. Hayashi, T. Matsuura, H. Fujishiro, Proc. IEEE Worksjop on Micro Electro Mechanical Systems (1994) 355.

3. Portions of this research were carried out at the Stanford Synchrotron Radiation Laboratory, a national user facility operated by Stanford University on behalf of the US Dept of Energy 

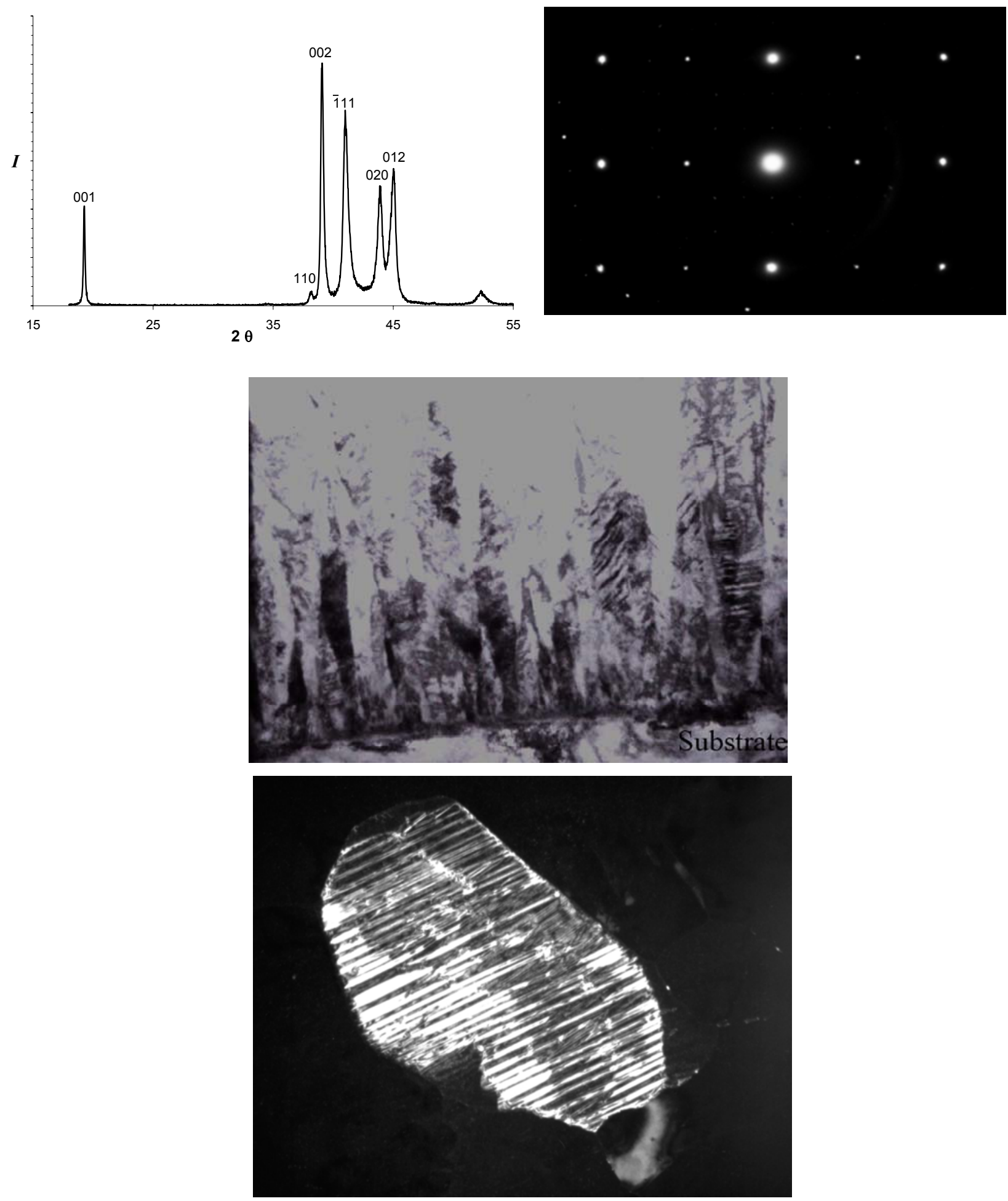

Figure 1. (top left) Diffraction profile of NiTi thin film verifying the crystallinity of the material. Figure 2. (top right) Diffraction pattern of martensite in the [001] zone axis orientation.

Figure 3. (middle) Cross sectional micrograph showing columnar growth.

Figure 4. (bottom) Martensite grain showing presence of twinning. 